\title{
Effects of Fungicides on Nitrogen Transformations in Soilless Potting Media
}

\author{
George C. Elliott' ${ }^{1}$ and Harvey J. Lang ${ }^{2}$ \\ Department of Horticulture, The Pennsylvania State University, University Park, PA 16802
}

Additional index words. urease, nitrification, benomyl, ethazol, metalaxyl, propamocarb

\begin{abstract}
Fungicides were applied at label rates to two commercial soilless potting media in which Iris siberica L. crowns had been potted and were subsequently grown under greenhouse conditions. Effects of fungicides on urea hydrolysis were inconsistent and generally insignificant. Ammonium oxidation was inhibited to varying degrees by Truban, Benlate, Banol, and Subdue. In a subsequent experiment, the same fungicides were added to cropped samples of the same media in vitro, followed 12 hours later by a solution containing urea and ammonium. Urea hydrolysis was essentially unaffected by fungicide treatments. Subsequent oxidation of ammonium was inhibited by Truban and Banol only in one medium. Transient accumulation of nitrite was inhibited by Truban but stimulated by Benlate in both media. When added to pure cultures of Nitrosomonas europea and Nitrobacter agilis, Truban completely inhibited oxidation of ammonium and nitrite. Benlate partially inhibited oxidation of ammonium and nitrite, while Subdue and Banal partially inhibited oxidation of ammonium but not nitrite. Chemical names used: [Methyl 1-(butylcarbamoyl)2-benzimidazolecarbamate] (benomyl); $N$ - (2,6-dimethylphenyl) $-N$ - (methoxyacetyl)alanine methyl ester (metalaxyl); [2chloro-6-(trichloromethyl)pyridine (nitrapyrin); 5-Ethoxy-3-(trichloromethyl)-1,2,4-thiadiazole (ethazol); Propyl[3(dimethylamino)propyl]carbamate monohydrochloride (propamocarb).
\end{abstract}

Soluble fertilizers used for production of crops in soilless media often contain high proportions of urea or ammonium nitrogen. Thus, hydrolysis of urea and oxidation of ammonium in these media influence $\mathrm{N}$ nutrition of plants (Elliott, 1986, 1988a, 1988b; Niemiera and Wright, 1986a, 1986b; Vetanovetz and Peterson, 1987a, 1987b; Wright, 1987). Accumulation of $\mathrm{NH}_{4}^{+}$can result from hydrolysis of organic $\mathrm{N}$ sources, such as urea, occurring more rapidly than oxidation of $\mathrm{NH}_{4}^{+}$to $\mathrm{NO}_{2}^{-}$. Accumulation of $\mathrm{NO}_{2}^{-}$results from oxidation of $\mathrm{NH}_{4}^{+}$to $\mathrm{NO}_{2}^{-}$ occurring more rapidly than oxidation of $\mathrm{NO}_{2}^{-}$to $\mathrm{NO}_{3}^{-}$. Transient accumulation of $\mathrm{NH}_{4}^{+}$or $\mathrm{NO}_{2}^{-}$is, therefore, the result of differences in activity of $\mathrm{NH}_{4}^{+}$-oxidizing and $\mathrm{NO}_{2}^{-}$-oxidizing microbes. This difference could be the result of differences in population sizes, species, or serotype, or environmental factors such as $\mathrm{pH}$, oxygen, or substrate concentration. Urea hydrolysis tends to increase medium pH (Vetanovetz and Peterson, 1987b), which favors increased activity of $\mathrm{NH}_{4}^{+}$oxidizers but may suppress $\mathrm{NO}_{2}^{-1}$ oxidizers (Bunt, 1988).

Urea hydrolysis and nitrification rates are generally low in uncropped media and in peat, but increase with time (Elliott, 1986; Vetanovetz and Peterson, 1987a), presumably associated with increased microbial populations rather than plant activity, since increases occur in media in the absence of plants (H.J.L. and G.C.E., unpublished; Vetanovetz and Peterson, 1987a). Urea hydrolysis in soil is catalyzed both by living organisms and exocellular urease (Bremner and Mulvaney, 1978).

Fungicides applied to control pathogens may also affect urea

Received for publication 3 Aug. 1989. Contribution 135, Dept. of Horticulture, The Pennsylvania State Univ. Authorized for publication as paper no. 8045 in the journal series of the Pennsylvania Agricultural Experiment Station. Where trade names are used, no discrimination is intended and no endorsement is implied by The Pennsylvania State Univ. Support for this project was obtained from the Pennsylvania Dept. of Commerce, W.R. Grace \& Co., Horticultural Products Div., Fogelsville, Pa., and the Dillon Research Fund of the Pennsylvania Flower Growers in a Ben Franklin partnership. We thank Sarah Ziemann and Stacy Kinzer for excellent technical assistance. The cost of publishing this paper was defrayed in part by the payment of page charges. Under postal regulations, this paper therefore must be hereby marked advertisement solely to indicate this fact.

'Present address: Dept. of Plant Science, Univ. of Connecticut, Storrs, CT 06269-4067

${ }^{2}$ Present address: Dept. of Horticulture, Iowa State Univ., Ames, IA 50011. hydrolysis and nitrification (Dhanaraj, 1988; Naraynana Rao, 1988). Ethazol and metalaxyl are patented as soil nitrification inhibitors for field-grown crops (Adams, 1987; Rideout and Jones, 1987). In a pine bark-peat-sand mixture, ethazol was an effective inhibitor of nitrification, but metalaxyl suppressed nitrification only slightly (Stratton and Good, 1987). Benomyl has been reported to stimulate accumulation of $\mathrm{NO}_{2}^{-1}$ plus $\mathrm{NO}_{3}^{-1}$ in soils (Mazur and Hughes, 1975; van Faassen, 1974). Van Faassen (1974) reported that 20 ppm benomyl in liquid medium inhibited oxidation of nitrite, but $200 \mathrm{ppm}$ inhibited oxidation of both ammonium and nitrite. Propamocarb may also affect nitrification in soil (Foster and McQueen, 1977; SimonSylvestre, 1985).

Although nitrification is generally associated with chemoautotrophic bacteria such as Nitrosomonas and Nitrobacter, acidtolerant heterotrophic microbes, especially fungi, may be significant contributors to nitrification in acid soils (Lang and Jagnow, 1986). Since peat- or bark-based media tend to be acidic, acid tolerance would be required for activity, and fungicides might thus be particularly inhibitory to heterotrophic nitrification.

The objective of this research was to test the effects of soildrench fungicides on urea hydrolysis and nitrification in soilless potting media.

\section{Materials and Methods}

Fungicides and development of nitrification activity during cropping (Expt. 1). Iris siberica were planted in four replicate 1.5- $\mathrm{dm}^{3}$ pots each of Metro-Mix 220 (MM220) and Metro-Mix 350 (MM350) (W.R. Grace, Fogelsville, Pa.). Exact composition of these media is proprietary, but MM220 contains sphagnum peat, vermiculite, and perlite, while MM350 contains sphagnum peat, vermiculite, and processed bark ash. Uncropped MM220 pH was 6.7, and uncropped MM350 pH was 6.6 , measured in a saturated slurry. The fungicides Banol, Benlate, Subdue, and Truban were applied according to label directions (Table 1) the next day. Samples were obtained from each pot with a core sampler the following day, and after 2, 4, and 9 weeks. All samples were air-dried at room temperature under a downdraft hood with HEPA-filtered air, thoroughly mixed and screened through a 2-mm mesh sieve before assays. Am- 
Table 1. Quantity of active ingredient of fungicides applied.

\begin{tabular}{llccc}
\hline \hline & \multirow{2}{*}{$\begin{array}{c}\text { Active } \\
\text { Fungicide }\end{array}$} & \multicolumn{3}{c}{ Experiment } \\
\cline { 3 - 5 } & & $\mathrm{mg} / \mathrm{pot}$ & \multicolumn{2}{c}{$\mathrm{mg} / \mathrm{tube}$} \\
Banal & Propamocarb & 320 & 2.7 & 16 \\
Benlate & Benomyl & 180 & 1.5 & 9 \\
Subdue & Metaxyl & 6 & 0.05 & 0.3 \\
Truban & Ethazol & 30 & 0.30 & 1.5 \\
\hline
\end{tabular}

monium oxidation rates were determined by measuring $\mathrm{NO}_{2}^{-}$ accumulation in the presence of chlorate (Elliott, 1988a). Urea hydrolysis was determined by measuring disappearance of urea in samples incubated $4 \mathrm{hr}$ at $37 \mathrm{C}$ with $5 \mathrm{mmol}$ urea $/ \mathrm{cm}^{3}$ medium in $50 \mathrm{~mm}$ Tris buffer, pH 8.0 (Elliott, 1988a). Data were statistically analyzed using SAS General Linear Model (GLM) (SAS, 1985), with treatments, media, and sample dates as class variables.

Fungicides in potting media in vitro (Expt. 2). Fungicide solutions were formulated at label concentrations and added at $2.5 \mathrm{ml} /$ tube to $15-\mathrm{cm}^{3}$ samples of medium (Table 1) in $50-\mathrm{cm}^{3}$ polyethylene screwcap conical bottom centrifuge tubes. An untreated control was included. Samples of cropped media were composites pooled from pots in which iris plants had been grown. Cropped MM220 pH was 6.7, and cropped MM350 pH was 5.6 , measured in a saturated slurry. Five milliliters of solution containing $7.5 \mathrm{~mm}$ urea and $0.75 \mathrm{~mm}\left(\mathrm{NH}_{4}\right)_{2} \mathrm{SO}_{4}$ was added 12 hr later. Soluble $\mathrm{N}$ compounds were extracted from samples after 0 to 7 days of incubation at $25 \mathrm{C}$ by adding $15 \mathrm{ml} 1.0 \mathrm{M}$ $\mathrm{KCl}$ containing $5 \mathrm{ppm}$ phenylmercuric acetate, shaking $1 \mathrm{hr}$ on a reciprocating platform shaker at 180 excursions/min, centrifuging $5 \mathrm{~min}$ at $2400 \times \mathrm{g}$, and filtering through medium retention, qualitative grade filter paper (VWR 613; VWR, San Francisco, Calif.). Four replicate tubes were extracted for each medium, treatment, and length of incubation. Urea, $\mathrm{NH}_{4}^{+}$and $\mathrm{NO}_{2}^{-}$were assayed calorimetrically (Bremner, 1982; Keeney and Nelson, 1982). Data were analyzed using the SAS GLM procedure (SAS, 1985) with media and fungicides as class variables and length of incubation as a continuous variable.

Fungicides in pure cultures (Exp. 3). Fungicide solutions were added to tubes containing $40 \mathrm{ml}$ autoclaved selective media for Nitrosomonas europea (ATCC strain 19718) and Nitrobacter agilis (ATCC strain 14123) at concentrations similar to those in the aqueous phase of the media in Expt. 2 (Table 1). There were five replicates per treatment. Additional treatments included 10 ppm nitrapyrin (N-Serve), an inhibitor of ammonium oxidation, and $10 \mathrm{mM} \mathrm{NaClO}_{3}$, an inhibitor of nitrite oxidation, to media for Nitrosomonas and Nitrobacter, respectively. Treated culture media were inoculated with pure cultures of the two microorganisms, mixed thoroughly, and incubated on a reciprocating shaker held in darkness at 25C. Aliquots of culture media were withdrawn at intervals and assayed calorimetrically for $\mathrm{NH}_{4}^{+}$or $\mathrm{NO}_{2}^{-}$. Banal interfered with the calorimetric determination of $\mathrm{NH}_{4}^{+}$in culture media (but not soilless media extracts), so appearance of $\mathrm{NO}_{2}^{-}$was used as a measure of $\mathrm{NH}_{4}^{+}$oxidation in pure cultures..

\section{Results}

Fungicides and development of nitrification activity during cropping Expt. 1). Fungicide applications at the start of cropping did not significantly affect the development of urea hydrolytic activity in either medium (data not shown). Truban decreased $\mathrm{NH}_{4}^{+}$oxidation, expressed as nitrite accumulation, in both media
(Fig. 1), but the effect was more persistent in MM220 than in MM350. Banol and Benlate inhibited NH", oxidation in MM220 at 0 and 4 weeks after application, respectively. Banol and Subdue inhibited $\mathrm{NH}_{4}^{+}$oxidation in MM350 up to 2 weeks after application.

Effects of fungicides in potting media in vitro (Expt. 2). Urea hydrolysis was not significantly affected by fungicide treatments in either medium, urea decreasing from $\approx 2.5$ to $\approx 0 \mathrm{~mol} \cdot \mathrm{m}^{-3}$ within $\approx 5$ days in both media. Ammonium accumulated to levels in excess of $3 \mathrm{~mol} \cdot \mathrm{m}^{-3}$ as urea was hydrolyzed (Fig. 2). In MM220, $\mathrm{NH}_{4}^{+}$levels declined significantly at the end of the incubation in the control, Benlate, and Subdue treatments, but not in the Truban or Banol treatments. Truban completely inhibited $\mathrm{NO}_{2}^{-}$accumulation, while Benlate markedly increased it, in both media (Fig. 3). In MM220, Banol inhibited $\mathrm{NO}_{2}^{-}$ accumulation during the final $48 \mathrm{hr}$ of the incubation.

Fungicides in pure cultures (Expt. 3). Ammonium oxidation ( $\mathrm{NO}_{2}{ }^{-}$formation) by Nitrosomonas was completely inhibited by $\mathrm{N}$-serve and Truban, and partly inhibited by Banal, Benlate, and Subdue (Fig. 4). Nitrite oxidation by Nitrobacter was completely inhibited by chlorate and Truban (Fig. 5). Benlate partially inhibited $\mathrm{NO}_{2}^{-}$oxidation in one trial (Fig. 5a), but in a replicate trial, in which initial rate of oxidation was slower, Benlate completely inhibited $\mathrm{NO}_{2}^{-}$oxidation (Fig. 5).

\section{Discussion}

The effects of fungicides on the development of $\mathrm{NH}_{4}^{+}$-oxidizing activity, $\mathrm{NH}_{4}^{+}$and $\mathrm{NO}_{2}^{-}$accumulation in soilless potting media in vitro, and on the activity of pure cultures of Nitrosomonas and Nitrobacter are indicative of the complex interrela-

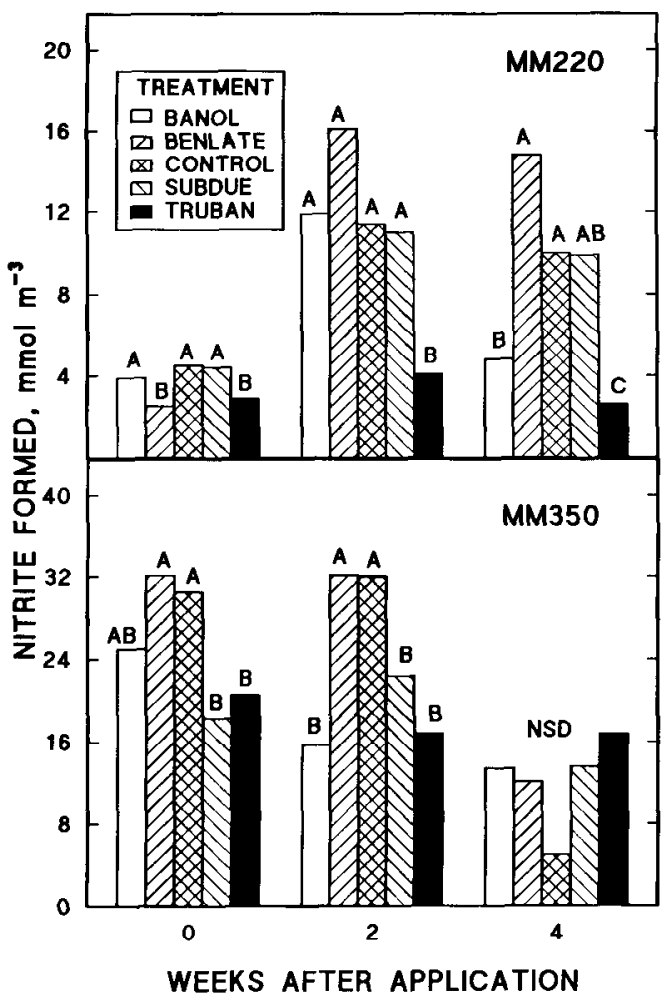

Fig. 1. Effect of fungicides on the development of $\mathrm{NH}_{4}^{+}$oxidation activity $\left(\mathrm{NO}_{2}^{-}\right.$accumulation in the presence of $\left.\mathrm{NaClO}_{3}\right)$ in soilless potting media under greenhouse conditions. Mean separation within a group by Waller-Duncan $\mathrm{k}$ ratio $t$ test, $\mathrm{k}=100$. NSD, no significant differences. 


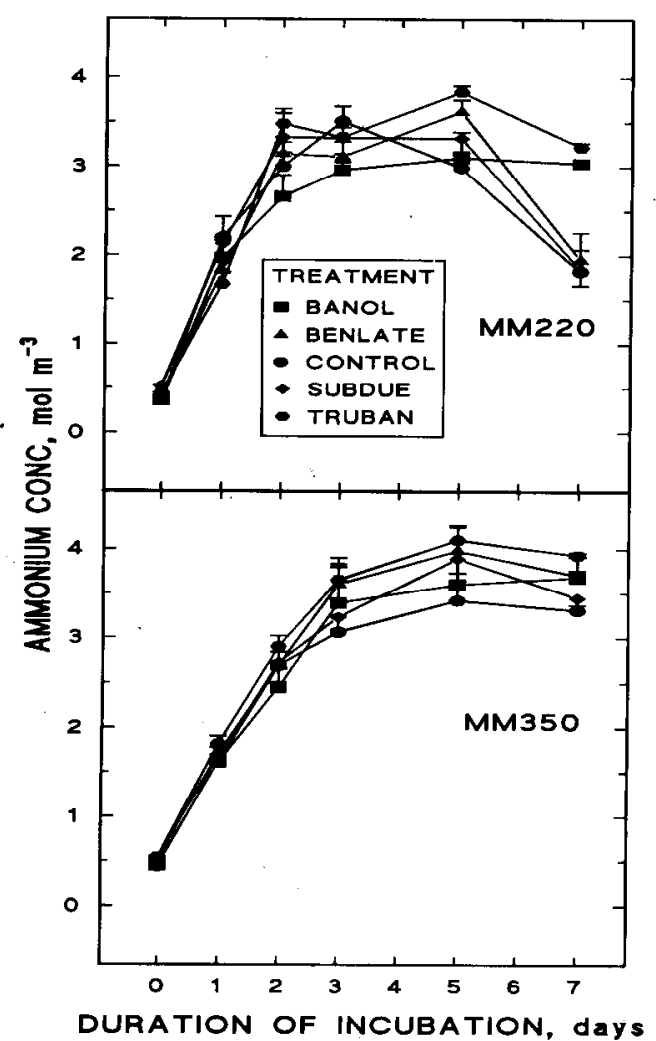

Fig. 2. Effect of fungicides on $\mathrm{NH}_{4}^{+}$accumulation in soilless potting media in vitro. Error bars, shown if greater than dimension of symbols, indicate standard deviation, $\mathrm{n}=4$.

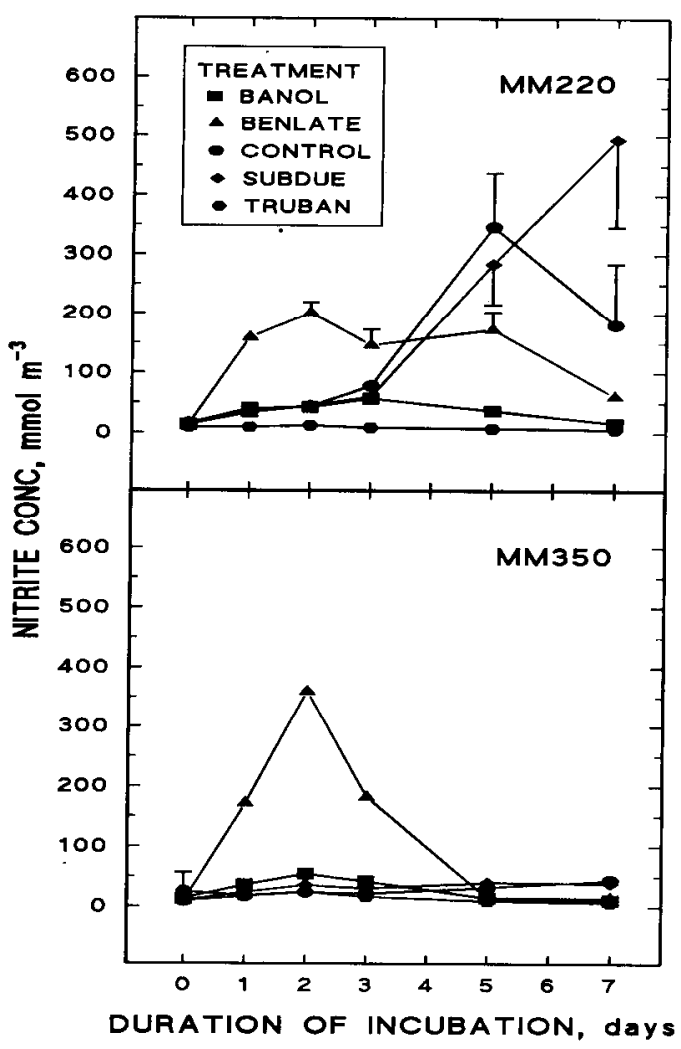

Fig. 3. Effect of fungicides on $\mathrm{NO}_{2}$ accumulation in soilless potting media in vitro. Error bars, shown if greater than dimension of symbols, indicate standard deviation, $\mathrm{n}=4$.

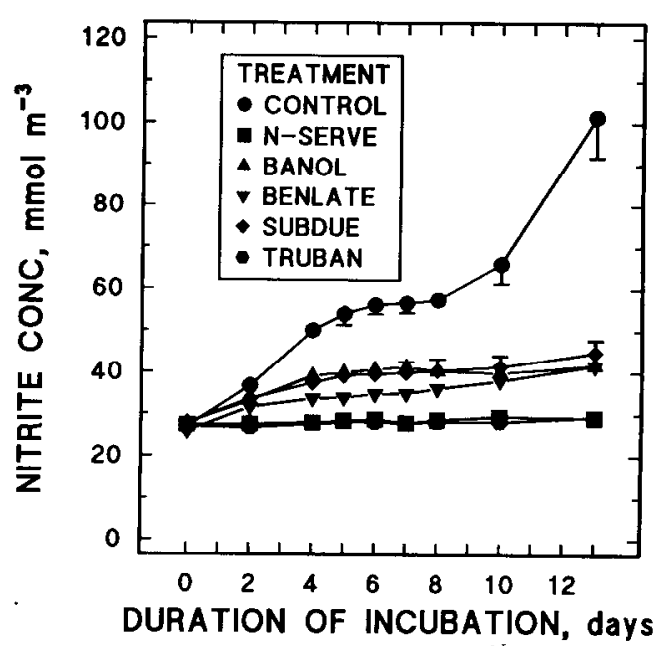

Fig. 4. Effect of fungicides on $\mathrm{NH}_{4}^{+}$oxidation ( $\mathrm{NO}_{2}$ accumulation) in pure cultures of Nitrosomonas europea. Standard deviations, $\mathrm{n}=5$, less than dimensions of symbols.

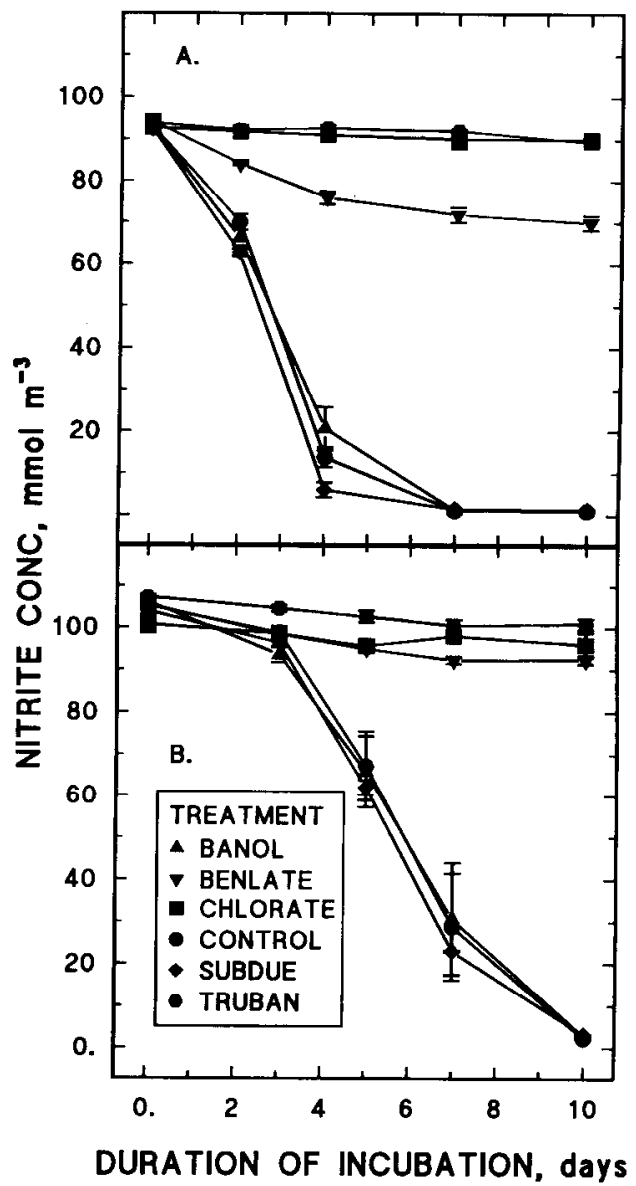

Fig. 5. Effect of fungicides on $\mathrm{NO}_{2}^{-}$oxidation in pure cultures o: Nitrobacter agilis. A and B represent independent trials. Error bars. shown if greater than dimension of symbols, indicate standard de. viation, $\mathrm{n}=5$.

tions of $\mathrm{N}$ transformations. For example, transient accumulation of $\mathrm{NO}_{2}^{-}$in media treated with Benlate (Fig. 3) evidently involves partial inhibition of both $\mathrm{NH}_{4}^{+}$and $\mathrm{NO}_{2}^{-}$oxidation by the batteria responsible for each step (Figs. 4 and 5). However, the degree of inhibition apparently is related to the activity (rate of oxidation) of the microbes involved (Fig. 5). 
Effects of fungicides on the activity of microbes in media in situ are likely to be different from effects in pure cultures or in vitro, since microbes in situ might escape suppression because of nonuniform distribution of active ingredient in pots or inactivation of active ingredient by media components. Some $\mathrm{N} \mathrm{H}^{+} 4$-oxidizing activity was maintained in media treated with Truban under greenhouse conditions (Fig. 1), although Truban completely inhibited activity in pure cultures and in vitro. In addition, the effects of fungicides in vitro could be modified in situ by the activity of plants. Uptake of $\mathrm{N}$ could rapidly change concentration of soluble $\mathrm{N}$ fractions in the medium, and alterations of substrate : product ratios and concentrations could affect the kinetics of oxidation.

Fungicide applications may have substantial effects on $\mathrm{N}$ transformations in soilless potting media, which could in turn be significant for plant growth. In particular, suppression of ammonium oxidation could be harmful for plants susceptible to ammonium toxicity (Haynes and Gob, 1978). Nitrite accumulation also might lead to toxicity (Birch and Eagle, 1969). Inhibition of vitrification by fungicides has been implicated in incidence of fungicide phytotoxicity (Powell, 1988). However, we are not aware of any direct evidence for either ammonium or nitrite toxicity occurring as a result of fungicide applications. Furthermore, it must be borne in mind that the effects we observed are both transient and highly variable. Thus, any potentially deleterious results of suppressed vitrification might occur only under unusual circumstances.

\section{Literature Cited}

Adams, G. 1987. Fungicide and fertilizer interactions in containerized plants. Mich. Assn. Nurserymen. Voice of MAN 30:3840.

Birch, P.D. and D.J. Eagle. 1969. Toxicity to seedlings of nitrite in sterilized composts. J. Hort. Sci. 44:321-330.

Bremner, J.M. 1982. Nitrogen-Urea, p. 699-710. In: A.L. Page, R.H. Miller, and D.R. Keeney (eds.). Methods of soil analysis. Part 2. Chemical and microbiological properties. 2nd ed. Amer. Soc, Agron./Soil Sci. Soc. Amer., Madison, Wis.

Bremner, J.M. and R.L. Mulvaney. 1978. Urease activity in soils, p. 149-196. In: R.G. Bums (cd.): Soil enzymes. Academic, New York.

Bunt, 1988. Media and mixes for container-grown plants. 2nd ed. Allen and Unwin, London.

Dhanaraj, P.S. 1988. Effects of pesticides on vitrification and denitrification, p. 43-118. In: R. Lal and S. Lal (eds.). Pesticides and the nitrogen cycle. vol. II. CRC, Boca Raton, Fla.

Elliott, G.C. 1986. Urea hydrolysis in potting media. J. Amer. Sot. Hort. Sci. 111:862-866.

Elliott, G. C.. 1988a. Rapid determination of urea hydrolysis and nitrification in potting media. HortScience 23:853-856.

Elliott, G.C. 1988b. Influence of fertigation methods on the develop- ment of urea hydrolytic activity in soilless potting media. HortScience 23:1024-1026.

Foster, M.G. and D.J. McQueen. 1977. The effects of single and multiple application of benomyl on non-target soil bacteria. Bul. Env. Contain. Toxicol. 17:477-484.

Haynes, R.J. and K.M. Gob. 1978. Ammonium and nitrate nutrition of plants. Biol. Rev. 53:465-510.

Keeney, D.R. and D.W. Nelson. 1982. Nitrogen-Inorganic forms, p. 643-698. In: A.L. Page, R.H. Miller, and D.R. Keeney (eds.). Methods of soil analysis. Part 2. Chemical and microbiological properties. 2nd ed. Amer. Soc Agron./Soil Sci. Soc. Amer., Madison, Wis.

Lang, E. and G. Jagnow. 1986. Fungi of a forest soil vitrifying at low pH values. Microbiol. Ecol. 38:257-265.

Mazur, A.R. and T.D. Hughes. 1975. Nitrogen transformations in soil as affected by the fungicides benomyl, Dyrene, and Maneb. Agron. J. 67:755-758.

Naraynana Rae, V.V.S. 1988. Effects of pesticides on ammonification, p. 1-42. In: R. Lal and S. La] (eds.). Pesticides and the nitrogen cycle. vol. II. CRC, Boca Raton, Fla.

Niemiera, A.X. and R.D. Wright. 1986a. The influence of vitrification on the medium solution and growth of Holly, Azalea and Juniper in a pine bark medium. J. Amer. Soc. Hort. Sci. 111:708-712.

Niemiera, A.X. and R.D. Wright. 1986b. Effect of liming rate on nitrification in a pine bark medium. J. Amer. Soc Hort. Sci. 111:713715.

Powell, C.C. 1988. Toxicity of growing medium drench fungicides. Ohio State Flower Grower's Hotline, no. 1.

Rideout, J.W. and J.L. Jones. 1987, Inhibition of vitrification in soil by metalxyl. Tob. Sci. 31:46-47.

SAS Institute, Inc. 1985. SAS user's guide: Statistics. version 5 (cd.). SAS Institute, Inc., Cary, N.C.

Schmidt, E.L. and L.W. Belser. 1982. Vitrifying bacteria, p. 10271042. In: A.L. Page, R.H. Miller, and D.R. Keeney (eds.). Methods of soil analysis. Part 2. Chemical and microbiological properties. 2nd ed. Amer. Soc. Agron. Soil Sci. Soc. Amer., Madison, Wis.

Simon-Sylvestre, G. 1985. Effets sur la nitrification de l'application simultanee d'un pesticide et d'un inhibiter denitrification. J. Environ. Sci. Health B20:525-537.

Stratton, M.L. and G.L. Good. 1987. The effect of selected fungicides on vitrification in an organic container nursery medium. HortScience 22:384. (Abstr.)

van Faassen, H. G." 1974. Effect of the fungicide benomyl on some metabolic processes, and on the number of bacteria and actinomycetes in the soil. Soil Biol. Biochem. 6:131-133.

Vetanovetz, R.P. and J.C. Peterson. 1987a. The effect of plant root growth on the fate of urea in sphagnum peat moss as affected by lime rate. HortScience 22:1129. (Abstr.)

Vetanovetz, R.P. and J.C. Peterson. 1987b. Urease activity and $\mathrm{pH}$ changes in a peat moss-based potting medium as influenced by lime source and lime rate following the addition of urea. J. Plant Nutr. 10:1889-1896

Wright, R.D. 1987. Nitrogen availability from urea in a pine bark medium. HortScience 22:70-72. 